\title{
Potassium limitation promotes the Sweetgum-Clitopilus symbiosis
}

\author{
long peng ${ }^{1}$, Xiaoliang Shan ${ }^{1}$, Yuzhan Yang ${ }^{1}$, Yuchen Wang ${ }^{1}$, Irina Druzhinina ${ }^{2}$, Xueyu \\ Pan $^{1}$, Wei Jin ${ }^{1}$, Xinghua He ${ }^{1}$, Xinyu Wang ${ }^{1}$, Xiaoguo Zhang ${ }^{1}$, Francis Martin ${ }^{3}$, and Zhilin \\ Yuan $^{1}$ \\ ${ }^{1}$ Research Institute of Subtropical Forestry Chinese Academy of Forestry \\ ${ }^{2}$ Nanjing Agricultural University \\ ${ }^{3}$ INRA Nancy
}

December 12, 2020

\begin{abstract}
Several species of soil free-living saprotrophs can sometimes establish biotrophic symbiosis with plants, but the basic biology of this association remains largely unknown. Here, we investigate the symbiotic interaction between a common soil saprotroph, Clitopilus hobsonii (Agaricomycetes), and the American sweetgum (Liquidambar styraciflua). Notably, the colonized root cortical cells contain numerous microsclerotia-like structures. Fungal colonization led to increased plant growth and facilitated potassium uptake, particularly under potassium limitation $(0.05 \mathrm{mM} \mathrm{K}+)$. The expression of plant genes related to potassium uptake is not altered during symbiosis, whereas the transcripts of three fungal genes encoding ACU, HAK, and SKC involved in $\mathrm{K}+$ nutrition is found in colonized roots. We confirmed the $\mathrm{K}+$ influx activities by expressing the ChACU and ChSKC genes into a yeast $\mathrm{K}+$-uptake-defective mutant. Upregulation of the ChACU under $0.05 \mathrm{mM} \mathrm{K}+$ and no $\mathrm{K}+$ conditions was demonstrated in planta and in vitro compared to normal condition $(5 \mathrm{mM} \mathrm{K}+)$. In addition, colonized plants displayed a larger accumulation of soluble sugars under $0.05 \mathrm{mM} \mathrm{K}+$. The present study highlights that potassium limitation promotes this novel tree-fungus symbiosis mainly through a reciprocal transfer of additional carbon and potassium to both partners, and the role of dual soil saprotroph/symbiotroph in tree nutrition.
\end{abstract}

\section{Hosted file}

Manuscript.pdf available at https://authorea.com/users/382493/articles/498394-potassiumlimitation-promotes-the-sweetgum-clitopilus-symbiosis 

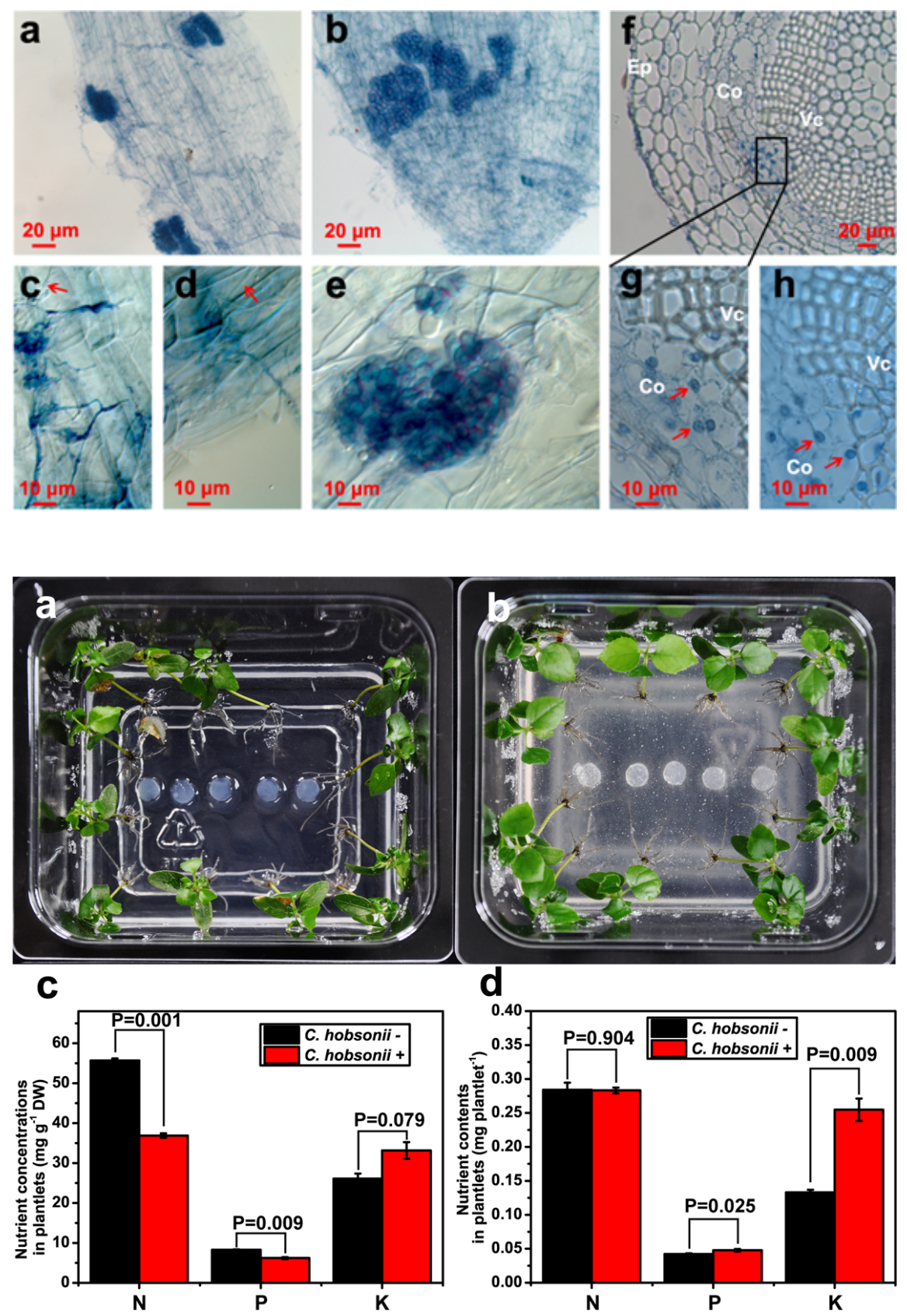




b

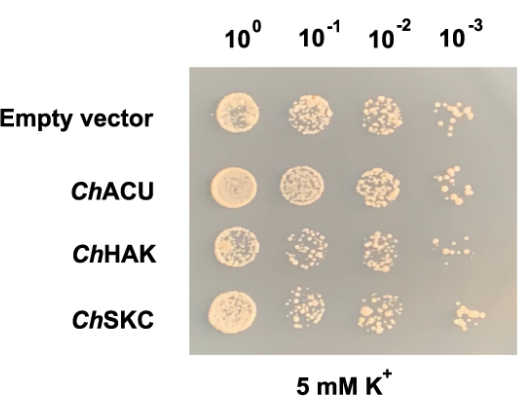

Empty vector

ChACU

ChHAK

Chskc



$2 \mathrm{mM} \mathrm{K}^{+}$ 
a

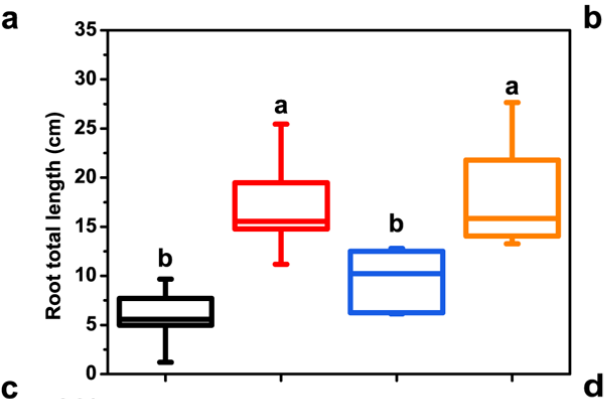

c

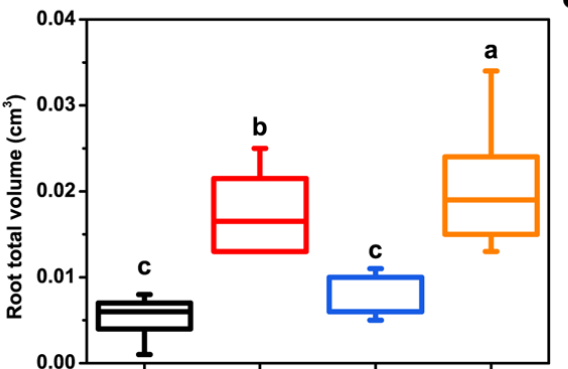

e


.
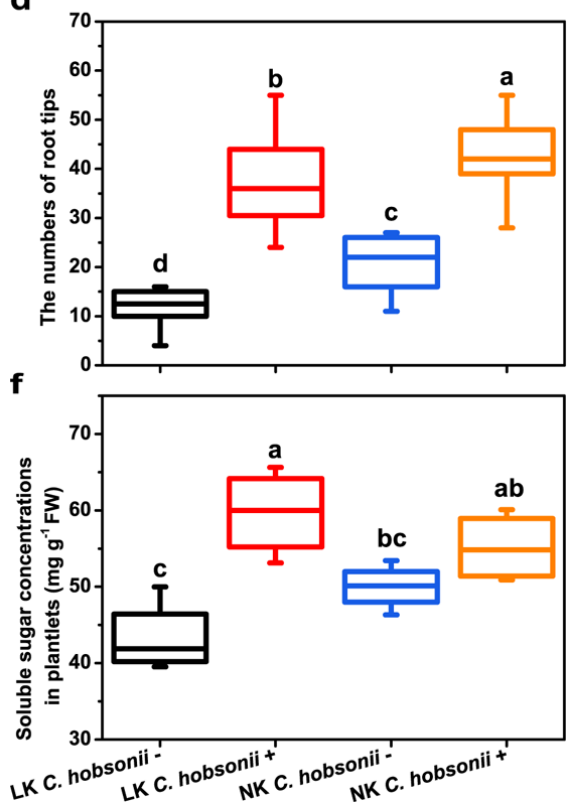

a

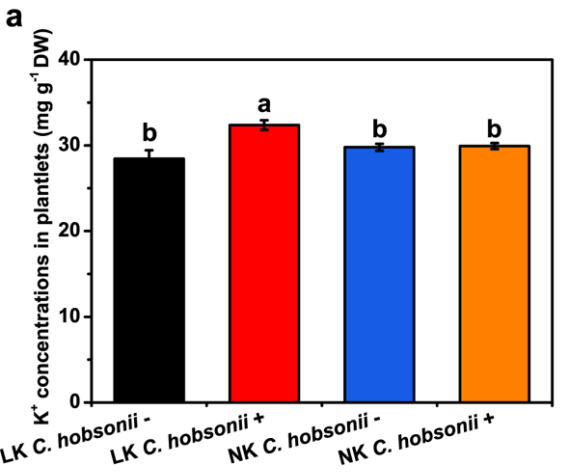

b




a
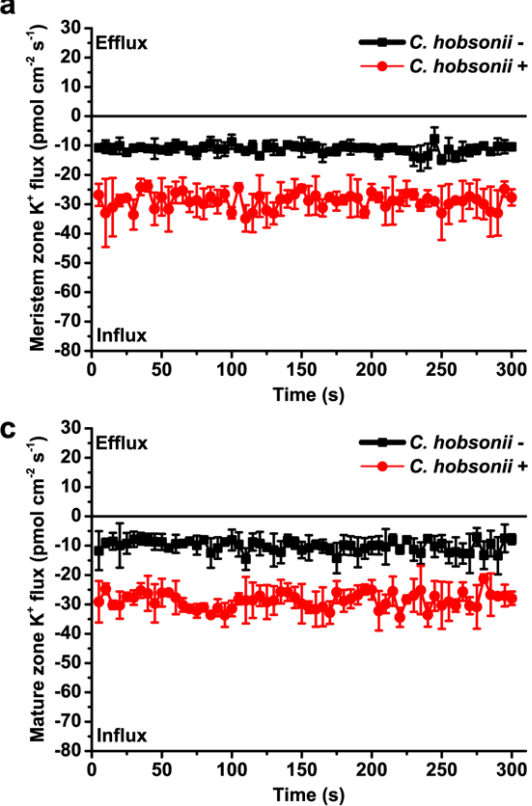

b


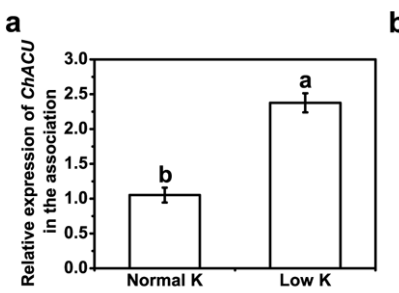

b
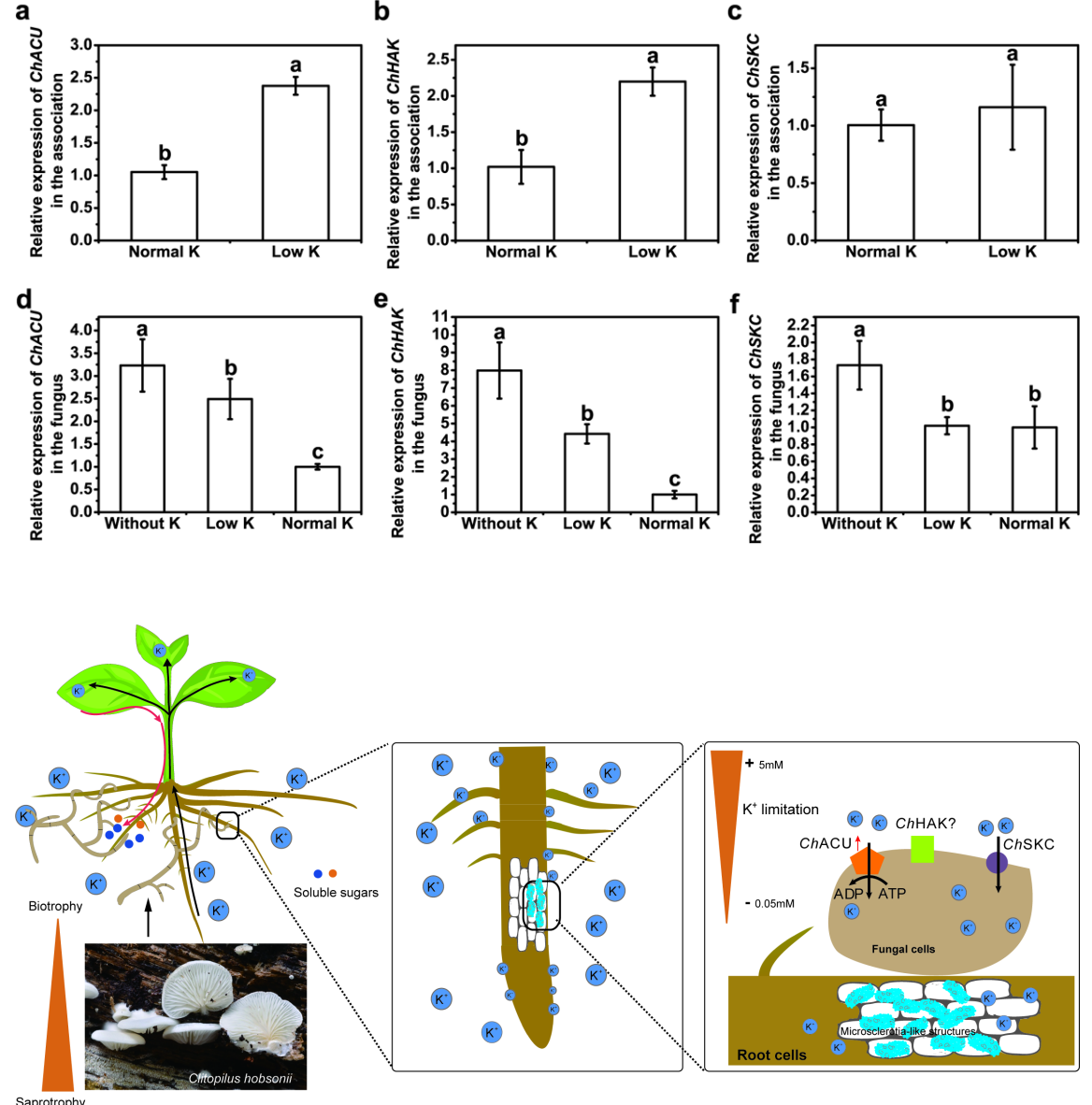